\title{
COVID-19, estado de excepción, autoritarismo y recrudecimiento de la violencia en Colombia*
}

\author{
COVID-19, state of exception, authoritarianism and the \\ resurgence of violence in Colombia
}

COVID-19, estado de exceção, autoritarismo e recrudescimento da violência na Colômbia

Efrén Danilo Ariza Ruiz**

\begin{abstract}
RESUMEN
El presente documento se enfoca en evidenciar cómo las categorías "estado de excepción", "autoritarismo neoliberal" y "biopolítica” permiten develar fenómenos sociales concretos causados por el tratamiento de la pandemia COVID-19 por parte del gobierno colombiano durante el período de confinamiento comprendido entre marzo y septiembre de 2020. Este objetivo es desarrollado a partir de una revisión sistemática de literatura, estadísticas oficiales e informes de entidades defensoras de derechos humanos, aplicando el método de revisión documental. Los resultados muestran que durante la pandemia se ha intensificado la violencia en Colombia, lo que se grafica en las violaciones al derecho internacional humanitario, la estigmatización y criminalización de la movilización social y la acción colectiva, las violaciones de los derechos humanos por parte de la fuerza pública, las masacres, el asesinato de líderes sociales, minorías étnicas, desmovilizados de las Fuerzas Armadas Revolucionarias de Colombia (FARC-EP). De
\end{abstract} Palabras clave: autoritarismo, biopolítica, COVID-19, estados de excepción, recrudecimiento de la violencia.

\footnotetext{
* El autor del artículo agradece profundamente los comentarios y observaciones realizadas por Gina Paola Rodríguez, Woody Edson Lourdior, Leonardo David Arias Cuellar y Yesid González Perdomo, que permitieron estructurar la versión final del documento; eternamente agradecido con su generosidad.

** Colombiano. Candidato a doctor en Filosofía, Universidad Santo Tomás, Colombia. Magíster en Filosofía Latinoamericana, Universidad Santo Tomás, Colombia. Economista, Universidad Nacional de Colombia. Académico de la Fundación Universitaria del Área Andina, Colombia. Líder del grupo de investigación QUIPUS. Bogotá, Colombia. eariza10@ areandina.edu.co
} 
igual modo, se ha incrementado la violencia estructural asociada a la pobreza, las medidas sanitarias y el acceso de los colombianos más vulnerables a los servicios de salud y a la vacunación.

\begin{abstract}
This paper focuses on how the categories "state of exception," "neoliberal authoritarianism," and "biopolitics" reveal concrete social phenomena caused by the Colombian government's treatment of the COVID-19 pandemic during the period of confinement between March and September 2020. We base our research on a systematic review of literature, official statistics, and reports from human rights organizations, applying the documentary review method. The results show that during the pandemic, violence has intensified in Colombia. The evidence shows violations of international humanitarian law, stigmatization, criminalization of social mobilization, and collective action. Also, human rights violations by security forces, massacres, the murder of social leaders, ethnic minorities, and demobilized members of the Revolutionary Armed Forces of Colombia (FARC-EP). Similarly, there has been an increase in structural violence associated with poverty, health measures, and access to health services and vaccination for the most vulnerable Colombians.
\end{abstract}

\section{RESUMO}

$\mathrm{O}$ artigo procura evidenciar como as categorias "estado de exceção", "autoritarismo neoliberal" e "biopolítica" permitem revelar fenômenos sociais concretos causados pelo tratamento da pandemia da COVID-19 pelo governo colombiano durante o período de confinamento entre março e setembro de 2020. Este objetivo é desenvolvido a partir de uma revisão sistemática de literatura, de estatísticas oficiais e de relatórios de organizações pela defesa dos direitos humanos, através da aplicação do método de revisão documental. Os resultados mostram que durante a pandemia a violência na Colômbia se intensificou, o que pode ser observado nas violações do direito internacional humanitário, na estigmatização e na criminalização da mobilização social e da ação coletiva, nas violações dos direitos humanos pelas forças de segurança, nos massacres, no assassinato de líderes sociais, minorias étnicas e desmobilizados das Forças Armadas Revolucionárias da Colômbia (FARC-EP). Igualmente, houve um aumento da violência estrutural associada à pobreza, às medidas sanitárias e ao acesso dos colombianos mais vulneráveis aos serviços de saúde e à vacinação.
Keywords: authoritarianism, biopolitics, COVID-19, states of exception, upsurge of violence.

Palavras-chave: autoritarismo, biopolítica, covid-19, estados de exceção, recrudescimento da violência. 


\section{Introducción: breve análisis del contexto}

La pandemia COVID-19 (SARS-CoV-2) nos sorprende, como señala Pachón Soto (2020), en la medida en que, de las entrañas mismas de la naturaleza, surge un virus que cuestiona la arrogancia del ser humano, usando el gran complejo civilizatorio creado por este, tales como los transportes, las grandes ciudades e incluso la globalización en general, para globalizarse a su vez y poner en jaque nuestra vida y nuestras instituciones. El virus se desliza utilizando el sistema-mundo moderno como un instrumento, como un medio.

El 16 de marzo de 2020 se adelantó un simulacro en la ciudad de Bogotá, el aislamiento obligatorio se decretó posteriormente a nivel nacional por el presidente Duque empatando la medida de simulacro y los respectivos toques de queda. Dicho aislamiento se ordenó a través de un decreto ordinario, sin acudir a la figura de estados de excepción, aspecto que justamente se ha criticado por los juristas considerando que la medida impone restricciones a la libertad de movilidad, por ejemplo, e incluso a la libertad de oficios (vendedores ambulantes, por ejemplo), restricciones que afectan derechos fundamentales lo que, por Constitución, no se puede hacer sino por una ley de tipo estatutario y, a lo sumo, a propósito de la emergencia, acudiendo justamente a los estados de excepción, pues en estos se expiden Decretos Legislativo que son de control automático de la Corte Constitucional y control político por el Congreso de la República.

A las citadas medidas (simulacro, toques de queda, aislamiento nacional obligatorio), precedió la declaratoria de emergencia sanitaria por el Ministerio de Salud y Protección Social mediante una resolución que se amparó en la declaratoria de pandemia advertida por la Organización Mundial de la Salud, OMS, resolución que sirvió como fundamento para adoptar tales medidas, y para que el presidente Duque y todos sus ministros decretaran el estado de emergencia económica, social y ecológica por la crisis social y los impactos económicos de la pandemia.

En el marco de dicho estado de emergencia, el Gobierno Nacional puede expedir los denominados Decretos Legislativos, para adoptar medidas que conjuren la crisis social. En esos casos, entonces, se permite que el Ejecutivo legisle excepcionalmente y lo haga por un tér- 
mino que no sea menor a 30 días y no supere los tres meses. En este sentido, durante 2020, se tuvo que proceder a hacer uso otra vez del mismo recurso.

El 26 de febrero de 2020 Giorgio Agamben (2020) publicó un texto en el cual hace evidente sus preocupaciones frente a los efectos que genera el temor causado por el virus:

Es el estado de miedo que evidentemente se ha extendido en los últimos años en las conciencias de los individuos y que se traduce en una necesidad real de estados de pánico colectivo, a los que la epidemia vuelve a ofrecer el pretexto ideal. Así, en un círculo vicioso perverso, la limitación de la libertad impuesta por los gobiernos es aceptada en nombre de un deseo de seguridad que ha sido inducido por los mismos gobiernos que ahora intervienen para satisfacerla. (p. 19).

Lo paradójico del caso colombiano es que las restricciones a derechos fundamentales no se imponen como consecuencia de los poderes de excepción, sino de los ordinarios que el presidente, gobernadores y alcaldes pueden ejercer a nivel nacional, departamental, distrital y municipal. Lo anterior es grave: lo adoptado en el marco de los poderes excepcionales es de obligatorio control automático - sin permiso, de oficio- por parte de la Corte Constitucional en el caso de los decretos legislativos y del Consejo de Estado y los Tribunales Contenciosos en el caso de otro tipo de decretos. Es decir, se pone en evidencia el gran poder que se concentra en el Ejecutivo bajo un gobierno de tipo presidencial que, aún sin acudir a los poderes de excepción, puede tomar medidas en contra del goce efectivo de los derechos fundamentales de las personas.

Los poderes de excepción no han servido para adoptar medidas que mitiguen el impacto en la restricción de derechos realizados por la vía ordinaria (medidas como la renta básica), sino para introducir reformas al sistema de pensiones, al sistema de transferencia de recursos públicos y su uso por parte de las autoridades territoriales, etc. Desde esta perspectiva, el gobierno de Duque aprovechó la pandemia para gobernar en lógica de excepción y sabiendo que el ejecutivo venía en un claro declive de legitimidad.

Este artículo presenta inicialmente un estado del arte y revisión de literatura para fundamentar teóricamente el análisis de las medidas to- 
madas por el gobierno colombiano para enfrentar la pandemia e identificar allí, elementos propios de la biopolítica e incluso necropolítica que se expresa en la consolidación de una comunidad inmunizada que asume como propio el discurso de la política del miedo que termina acentuando la violencia y la desigualdad en el país.

Posteriormente se realiza un análisis documental que evidencia que la situación de pandemia, aparejada de la restricción de libertades fundamentales por la vía ordinaria que impuso confinamientos, terminó por acentuar las desigualdades y las violencias ya existentes y ocultar a los que de por sí ya estaban ocultados, excluidos y marginados, en el entendido que son "otros" que no importan, personas a quienes se les niegan los derechos pese a tener derechos. Así mismo, la situación de pandemia posibilitó que los poderes de excepción se utilizaran para gobernar y mantener invisibilizados a "los otros sin importancia", a los homo sacer, para desplazar aún más el cumplimiento de los acuerdos de paz, y adoptar medidas que profundizan la marginalización social. A través del estado de excepción se ha reforzado y legitimado su inacción frente al espiral de violencia del que son víctimas los líderes sociales, excombatientes desmovilizados firmantes del acuerdo de paz, jóvenes y en general los sectores sociales más vulnerables del país.

El artículo finaliza con unas conclusiones que persiguen visibilizar el incremento de la violencia y desigualdades ya existentes en el país durante el período de aislamiento obligatorio y avizorar líneas de acción para contener el mencionado ejercicio autoritario, a partir de dos conceptos emancipadores y humanos: la "biocracia" y el "cualsea".

\section{Estado del arte y revisión de la literatura}

Los resultados de la revisión sistemática de literatura se dividen en tres dimensiones de análisis: en primer lugar, los análisis de las medidas tomadas por los gobiernos para enfrentar la pandemia en clave biopolítica, donde emergen conceptos importantes como el de la comunidad inmunizada por el miedo, el homo sacer e incluso la necropolítica. Una segunda dimensión hace referencia a las implicaciones en términos de los principios del Estado social de derecho, el ejercicio de las libertades fundamentales, y situación de los derechos humanos; que tiene el acudir a estados de excepción, configurando lo que se puede denominar "estado de miedo". El análisis de la biopolítica y el abuso de 
la figura de los estados de excepción permite que emerja un oxímoron: el concepto de dictadura democrática que se materializa en el autoritarismo neoliberal, constituyendo la tercera dimensión de análisis.

\section{Biopolítica, comunidad y homo sacer en el marco de la pan- demia}

El concepto de biopolítica es uno de los grandes aportes de Michel Foucault, a través de sus libros: Historia de la sexualidad: La voluntad del saber (2002); Vigilar y Castigar. Nacimiento de la prisión (1999); Defender la sociedad Curso en el Collège de France (1975- 1976) (1997) y, por supuesto, El Nacimiento de la Biopolítica. Curso del Collège de France (1978-1979) (2009). Así, la biopolítica:

Se puede definir como un conjunto de prácticas que controlan la vida humana a través de la tecnología del poder, enmarcado en la sociedad disciplinaria y de control. En este sentido, los cuerpos, son considerados, como entes a ser optimizados, con la finalidad de ser integrados en sistemas de obediencia. (Burgos, 2020, p. 87).

Foucault (1997) propone la fórmula "hacer vivir, dejar morir" para explicar la modalidad propia de ejercicio del biopoder. Así mismo sostiene que "la biopolítica vino a transformar, sustituir, completar, penetrar, atravesar, modificar e invertir, al modelo soberano de ejercicio del poder" (p. 178).

Sin embargo, en consonancia con Burgos (2020), "ha ocurrido una serie de transformaciones que implican el surgimiento de otras formas de poder tecnológico en el sistema político económico neoliberal preponderante en occidente que superan el concepto original enunciado por el filósofo francés" (p. 88).

La crisis del COVID-19 abre un espacio para ampliar aún más no solo la vigilancia, sino también un control más acérrimo de nuestros datos, esta vez amparados en la crisis sanitaria, lo que implica un crecimiento excesivo de los dispositivos de control, cámaras, seguimiento a través de georreferenciación y acceso de los gobiernos a datos de ordenadores y celulares (Burgos, 2020; Quintero Cordero 2020). Estos límites a la libertad tienden a consolidar una uniformidad de pensamiento, a partir de una aparente sensación de libertad, aunque en realidad se le está controlando plenamente. 
A nivel mundial generan temores las políticas de seguimiento y control como respuesta a la pandemia COVID-19 implementadas por parte del Estado y sus instituciones. "Inquieta la idea que, una vez superada la pandemia, el uso de los datos personales y la invasión de la privacidad sea legitimada como un método necesario para el bien común" (Burgos, 2020, p. 92). Autores como Da Rocha Seijas (2020), Garzón Buenaventura y Álvarez Orduz (2020) y Schubert (2020) ponen en diálogo la visión foucaultiana de biopolítica con la propuesta por Agamben y retomada por Achille Mbembe que se traduce en la emergencia del concepto de necropolítica.

Giorgio Agamben fusiona el concepto de biopolítica de Foucault, con la teoría de la soberanía del jurista alemán Carl Schmitt y al respecto señala que la novedad de la biopolítica moderna es la entrada de la vida desnuda biológica en los mecanismos y cálculos del poder estatal en la forma de una inclusión exclusiva, en dónde los cuerpos son incluidos en la forma de su abandono a la muerte, desprovistos de toda humanidad (1998), es decir, "el abandono de la vida se produce cuando el Estado soberano se convierte en un Estado de excepción y las libertades son suspendidas, eliminadas en nombre de una aparente amenaza con el fin de perpetuar todo tipo de calamidades" (Correa, 2020, p. 77).

Schubert (2020) introduce una distinción fundamental entre la biopolítica tradicional centrada en el Estado represivo y la biopolítica democrática centrada en el organismo emancipador de los activistas y la comunidad; pero llama la atención en torno al surgimiento de una nueva forma de normalización biopolítica y represión que se produce en la pandemia: la biopolítica populista. Así mismo, denuncia que en tiempos de crisis la comunidad en general tiende a la biopolítica populista, haciendo juicios morales impulsados por el miedo, ignorando el impacto social desigual de las medidas de confinamiento y alerta sobre la necesidad de defender la democracia frente a estas ambiciones autoritarias. A partir del concepto de comunidad, autores como Rengifo López (2020) y Quintero Cordero (2020) retoman la propuesta realizada por Roberto Esposito (2003) alrededor del concepto de comunidad inmunizada.

Estos autores señalan que la comunidad se inmuniza con la modernidad. La noción moderna de comunidad — que es un principio 
fundamental del Estado nación-, se funda sobre el elemento que aglutina, como la nacionalidad, el idioma y la religión. Esto de por sí implica la exclusión del otro, del que no pertenece: todo aquel que no comparte ese lazo común se convierte en sospechoso, genera temor y desconfianza.

El hecho de que en Colombia existan otros susceptibles de ser subsumidos como homo sacer es lo que lleva a que, con pandemia o sin ella, se entiendan como vidas sin importancia, como vidas sacrificables con anuencia del derecho. Agamben muestra que el fundamento del poder se encuentra en la captura de la vida, en hacer de la vida objeto de control y disciplina, en fin, biopoder que en el derecho moderno funciona bajo la lógica de la excepción permanente. No es que hoy día se haga uso del estado de excepción "formal" y "legal" para gobernar sobre la vida de los seres humanos, sino que lo que sucede es que el poder y el derecho moderno funcionan lógica, histórica y estructuralmente así. En este sentido, la comunidad nacional colombiana hace varias décadas estableció sus homo sacer: precisamente los otros, los excluidos, los históricamente despojados y revictimizados en las periferias urbanas y rurales.

\section{Estado social de derecho y pandemia}

Autores como Estupiñán Achury (2020) y Quintero Cordero (2020) coinciden en enunciar una serie de obligaciones irrenunciables del Estado frente a sus ciudadanos, entre ellas garantizar un sistema de salud pública gratuita y eficiente, que proteja la vida sobre todas las cosas y sin distinciones, antes de llegar a la intervención social por medio de políticas de seguridad extrema que limiten la libertad y empoderen a gobiernos con tendencias fascistas y populistas.

La mayoría de los estados del mundo buscaron opciones de estado de excepción o de emergencia para la pandemia. En América Latina, la regla ha sido el estado de emergencia, estado de excepción por catástrofe, estado de calamidad pública, la cuarentena, la suspensión de clases, el desarrollo sui generis de las ramas del poder público, cierre de fronteras, el confinamiento, el teletrabajo, prohibición de eventos, suspensión de términos en la administración de justicia, las limitaciones en materia de locomoción, excepto para lo que se ha denominado casos de excepción, que en el tema colom- 
biano ha impactado tantos sectores como las cifras de aumento por contagio y movilización (a 9 de julio de 2020, somos el tercer país de América Latina con mayor contagio). (Estupiñán Achury, 2020, pp. xviii-xix).

El sistema de gobierno presidencial, que para el caso de América Latina y Colombia en particular ya sufría de vicios de mesianismo, autoritarismo, concentración del poder y corrupción, se ha visto fortalecido. Como señala Estupiñán Achury (2020) varios mandatarios estaban seriamente cuestionados en la fase previa de la crisis sanitaria y en el caso colombiano "no han logrado convencer ni desarrollar políticas públicas en clave de protección a la vida, la economía y la seguridad" (p. xxiii).

\section{Neoliberalismo autoritario y dictaduras democráticas}

La opción tomada por la mayoría de gobiernos de acudir a estados de excepción terminan por fortalecer dos fenómenos que se venían presentando tiempo atrás en la región: la emergencia de un neoliberalismo autoritario y, a partir de un populismo con tintes fascistas, unas dictaduras democráticas que analizan Ramírez Gallegos (2020), Quintero Cordero (2020) y Díaz Arias y Viales Hurtado (2020).

Para la Real Academia de la Lengua Española, un oxímoron es "la combinación en una misma estructura sintáctica de dos palabras o expresiones de significado opuesto que originan un nuevo sentido, como un silencio atronador". El sentido literal del oxímoron suele resultar en absurdos semánticos, como dictaduras democráticas. Estas dos palabras a priori jamás debiesen estar juntas. No obstante, parece ser que es muy cercano a lo que describe, hoy en día, lo que sucede en muchos países de Latinoamérica y en otros lugares del mundo. (Ramírez Gallegos, 2020, p. 5).

Lo anterior configura una situación extremadamente riesgosa, porque como señala Quintero Cordero (2020), en nombre de la vida los gobiernos violentan derechos humanos, lo que puede generar un retraso significativo en el terreno previamente ganado por sectores excluidos (los otros) que se ejemplifica perfectamente en Colombia con el asesinato de líderes sociales, firmantes del acuerdo de paz, el retorno de la guerra y el reclutamiento de menores de edad por parte de grupos al margen de la ley y su asesinato por parte de la fuerza pública 
y el incremento del desplazamiento forzado. En este sentido, Agamben (1998) señala:

El soberano está, al mismo tiempo, fuera y dentro del ordenamiento jurídico; cae, pues, fuera del orden jurídico normalmente vigente sin dejar por ello de pertenecer a él, puesto que tiene competencia para decidir si la constitución puede ser suspendida "in toto" (...) El soberano, al tener el poder legal de suspender la validez de la ley, se sitúa legalmente fuera de ella. (p. 27).

Es conocida la postura crítica de Agamben frente al concepto de estado de excepción verdadero esgrimido por Walter Benjamin (1940), en su tesis VIII de su ensayo Sobre el concepto de historia. Sin embargo, el aporte de Benjamin es fundamental para entender las implicaciones del accionar del gobierno colombiano.

La tradición de los oprimidos nos enseña que el "estado de excepción" en que ahora vivimos es en verdad la regla. El concepto de historia al que lleguemos debe resultar coherente con ello. Promover el verdadero estado de excepción se nos presentará entonces como tarea nuestra, lo que mejorará nuestra posición en la lucha contra el fascismo. La oportunidad que este tiene está, en parte no insignificante, en que sus adversarios lo enfrentan en nombre del progreso como norma histórica. El asombro ante el hecho de que las cosas que vivimos sean "aún" posibles en el siglo veinte no tiene nada de filosófico. No está al comienzo de ningún conocimiento, a no ser el de que la idea de la historia de la cual proviene ya no puede sostenerse. (Benjamin, 1940, p. 6-7).

Lo que está planteando Benjamin es la necesidad de abandonar las concepciones dominantes de la historia para luchar contra el fascismo, para visibilizar la historia de las víctimas y de los oprimidos que han sido invisibilizados por la violencia fundadora y conservadora del derecho. Un fascismo fundamentado en un estado de derecho fuerte y que utiliza el estado de excepción como mecanismo de dominación que contemporáneamente emerge de forma peligrosa.

Frente a este panorama, es necesario acudir a la esperanza y a la acción colectiva y se identifican dos conceptos en los cuales fundamentarlas: la biocracia y el cualsea. Caldera Ynfante (2020) desarrolla el concepto: 
Se define la biocracia como el poder político fundado en el cuidado y protección de la vida y se relaciona con el derecho fundamental a un nuevo orden mundial (NOM), consagrado en el artículo 28 de la Declaración Universal de los Derechos Humanos (DUDH, 1948) que imperativamente obliga a los estados a hacer plenamente efectivos todos los derechos humanos (DDHH) de todas las personas -inherentes a la dignidad humana - para que logren felicidad personal, concretando en libertad y autonomía su proyecto de vida valioso, sin daños ni arbitrariedades, cumpliendo el deber estatal de respetar, proteger y garantizar los $\mathrm{DDHH}$, como reto de la comunidad internacional a favor de la familia humana en la pospandemia de la COVID-19 (p. 33).

La biocracia es el poder político fundado en el cuidado y protección de la vida. Se deriva del griego bio (vida) y cratos (poder). Un poder basado en la vida, para la vida y por la vida inherente a la dignidad humana. La apuesta de Caldera Ynfante (2020) es interesante porque a diferencia de los conceptos de biopolítica o necropolítica reflexiona acerca de la posibilidad de establecer una relación positiva entre el poder político y la vida humana con autonomía y libertad, y que se convierta en epicentro de la legitimidad democrática en tanto instrumento de la comunidad política para asegurar la vida social armónica, la gestión del conflicto y la violencia, bajo la racionalidad humana, el principio de legalidad y la primacía de la dignidad humana.

Concebir un estado de derechos humanos o estado humanista de derecho, donde el poder político está en función de la vida, implica un giro copernicano, de suyo, frente a la configuración del estado de derecho, viniendo a instituir el estado de derechos, en plural, afincado en la dignidad humana donde, si bien el Estado debe someterse al derecho - como ordenamiento o sistema jurídico- al unísono debe cumplir, taxativamente, con la obligación consustancial a su razón de ser pública que le obliga a cuidar y proteger la vida de la persona humana, cumpliendo con el deber de promover, respetar, garantizar y proteger efectivamente todos los DDHH de sus ciudadanos y todo habitante que viva en su territorio. En tal sentido, se aprecia una mutación, un trasegar del Estado (social o constitucional) de derecho clásico al que aquí se ha denominado 
como el estado de derechos humanos o también el estado humanista de derecho. (Caldera Ynfante, 2020, p. 39).

En consonancia con Rengifo López (2020) es necesario pensar en un concepto de solidaridad diferente, para contrarrestar la exposición a la muerte e impactar las condiciones de vida de los sujetos más vulnerables. De igual forma, es preciso desde la acción colectiva romper con la idea de pertenencias basadas en nacionalidad, credo, clase o cualquier otro supuesto rasgo compartido. Todo tipo de valoración respecto de un individuo debe partir de su humanidad.

Por su parte, Agamben (1996) desarrolla un concepto humano y emancipador: el cualsea, que permite construir una comunidad alejada de cualquier rasgo "supuestamente" común que termina excluyendo. La esencia general que permite construir esa nueva comunidad es una singularidad, esto es, la condición de sujetos que compartimos todos los seres humanos: el cualsea, "el ser tal que, sea cualsea, importa" (p. 9)".

\section{Método}

Se realiza una revisión sistemática de literatura en bases de datos académicas como Google Scholar, Proquest, Latindex, Dialnet, Science Direct y Scopus con las palabras clave: autoritarismo, COVID-19, biopolítica, neoliberalismo, estado de derecho y pandemia, estado de excepción, movilización social, violencia policial y Colombia, tomando como criterios de inclusión los aportes teóricos o metodológicos. Posteriormente se construyeron fichas bibliográficas, fichas de trabajo y se sistematizó la información a través de resúmenes analíticos de lectura RAES.

Los resultados consignados en este artículo parten de un tratamiento riguroso de los documentos y de la información obtenida de estadísticas oficiales, informes de organizaciones encargadas de la defensa de los derechos humanos tales como el Comité Internacional de la Cruz Roja (CICR), Human Rights Watch, el Instituto de estudios para el desarrollo y la paz, INDEPAZ, y la Red Popular De Derechos Humanos de Bogotá. Este conjunto de datos permitió realizar un análisis contextual y teórico.

Se llevó a cabo un análisis documental que relacionó las estadísticas, cifras y medidas tomadas por el Gobierno para mostrar que estas últimas se enmarcan en una biopolítica e incluso en una necropolítica. 
El análisis buscó poner a dialogar categorías teóricas (estado de excepción, biopolítica, autoritarismo neoliberal) y evidencia empírica (obtenida a través de la revisión documental), para intentar comprender lo que está pasando en Colombia durante la pandemia.

\section{Resultados}

Antecedentes al período marzo-septiembre 2020: la consolidación del homo sacer en Colombia

Lo que está pasando en Colombia es una consolidación del homo sacer. Con ayuda de la cuarentena, existe una serie de antecedentes cercanos al período de estudio comprendido entre marzo y septiembre de 2020 que dan cuenta de que, desde la llegada al poder de Iván Duque, los abusos de autoridad y delitos cometidos por parte de la fuerza pública han configurado lo que se denomina en este estudio autoritarismo neoliberal y dictadura democrática.

En 2019, el periódico New York Times, la revista Semana y Human Rights Watch publicaron documentos que mostraban que durante ese año el Ejército revivió políticas que generan incentivos perversos que se materializaron en los mal llamados "falsos positivos", esto es, asesinatos cometidos por la fuerza pública contra jóvenes pobres que fueron victimizados por su condición, atraídos con falsas promesas de empleo y que posteriormente fueron revictimizados al ser acusados falsamente de ser guerrilleros, con agresivas expresiones como las del expresidente Uribe: "No estaban recogiendo café".

De la misma manera, en diciembre de 2019, la revista Semana publicó evidencias donde nuevamente soldados del Ejército ejercieron acciones de vigilancia ilegal contra periodistas, defensores de derechos humanos y algunos funcionarios públicos (Human Rights Watch, 2021), lo que permite inferir que todo aquel que se exprese en contra del discurso de las políticas oficiales es objeto de seguimientos e intimidaciones.

El 21 de marzo de 2020, "24 internos murieron y 76 resultaron heridos cuando policías reprimieron los disturbios en la cárcel La Modelo, en Bogotá. Hasta septiembre, no se había imputado a nadie en relación con las lesiones y muertes" (Human Rights Watch, 2021, s/p). Los reclusos se convierten en individuos residuales cuya vida le importa poco a la comunidad inmunizada. Frente a este incidente y a uno más recien- 
te donde murieron reclusos en una estación de policía en Soacha, las expresiones de muchos ciudadanos en programas de opinión, radio y redes sociales coinciden en no cuestionar la responsabilidad del Estado, o de la fuerza pública ante estas muertes, sino que giraron más en torno al porqué se debía respetar la vida de estas personas tratándose de delincuentes.

Así mismo, Human Rights Watch consignó que "al menos seis civiles murieron entre marzo y junio durante operativos policiales para erradicar los cultivos de coca en varias partes del país, según informaron los medios de comunicación y organizaciones locales de derechos humanos" (2021). En contraposición, el gobierno de Duque y su caja de resonancia - los medios de comunicación tradicionales-, explican que el espiral de violencia se debe al narcotráfico y la única manera de enfrentarlo es a través de la erradicación forzosa y el uso de glifosato (herbicida que tiene efectos nocivos en las personas y animales), incumpliendo en este sentido los planes de sustitución voluntaria de plantaciones, sin ofrecer alternativas económicas a estas comunidades que, de por sí, ya están siendo victimizadas por el abandono y la corrupción estatal.

Hasta octubre de 2020, la Oficina del Alto Comisionado de las Naciones Unidas para los Derechos Humanos (ACNUDH) había documentado el asesinato de 49 defensores de derechos humanos en ese año y se encontraba verificando otros 50 casos. Además de los defensores de derechos humanos, líderes de comunidades afrodescendientes y comunidades indígenas son las principales víctimas de este tipo de violencia, exclusión y racismo.

\section{Violaciones al derecho internacional humanitario}

Es evidente el incremento de las violaciones al derecho internacional humanitario en Colombia en el período de pandemia. Una síntesis del más reciente informe realizado por el Comité Internacional de la Cruz Roja (CICR) socializado por Hola News (2021), permite identificar lo siguiente: se presentan cinco conflictos internos entre grupos armados y el Estado, principalmente en siete regiones del país, generando casi mil violaciones al derecho internacional humanitario.

Según Hola News (2021), el CICR habría reportado la ocurrencia de 114 casos de desaparecidos en Colombia durante 2020, de los 
cuales 102 eran civiles, incluyendo diez menores de edad. Así mismo, 28.000 personas fueron sometidas a confinamientos forzosos por parte de grupos armados al margen de la ley, siendo el Departamento del Chocó el más afectado por esta situación con 21.000 personas, las que fueron desplazadas forzosamente de sus territorios, la mitad de ellas en el suroccidente del Departamento de Nariño. De igual modo, 389 personas fueron víctimas de artefactos explosivos en 41 municipios del país, la cifra más alta en cuatro años; lo más lamentable es que, fruto de la implementación del acuerdo de paz durante el año 2019, no se había registrado ningún incidente.

\section{Retorno de las masacres}

Una lamentable práctica que se recrudece durante el período de aislamiento obligatorio es la de las masacres, aun cuando el gobierno de Duque insistió en utilizar el eufemismo de homicidios colectivos para nombrar esta realidad. Durante el 2020 se presentaron 90 masacres, las que arrojaron un total de 381 muertos. Al respecto, para el CICR:

La pandemia ha sido el medio y la oportunidad para hacerse con más territorio y las zonas disputadas fueron sobre todo las del Pacífico, el suroeste y la región noroccidental de Antioquia, corredores clave para la salida de mercancías ilícitas del país hacia el mar, tanto Pacífico como el Caribe. Las fuerzas armadas estatales se enfrentan en estos territorios con cuatro grupos armados (la guerrilla del ELN, el Ejército Popular de Liberación, EPL, el mayor grupo criminal del país - las Autodefensas Gaitanistas de Colombia- y un grupo de disidencias de las FARC bajo mando centralizado), a lo que se suma también el enfrentamiento por control territorial entre el ELN y el EPL. (Hola News, 2021, s/p).

Desagregando la información de la Figura 1 por Departamento, el de Antioquia - fortín electoral y zona de origen del caudillo que lidera el partido de Gobierno, Álvaro Uribe Vélez ${ }^{1}-$, encabeza esta macabra estadística.

1 Allí comenzó su carrera política: jefe de bienes de las empresas públicas de Medellín en 1976, alcalde de Medellín en 1982, senador por el Departamento de Antioquia, gobernador de Antioquia entre 1995 y 1997, período en el cual se rompe el récord de masacres y violaciones a los derechos humanos en el Departamento. 
Figura 1.

Masacres y víctimas en Colombia 2020 por Departamentos 2020

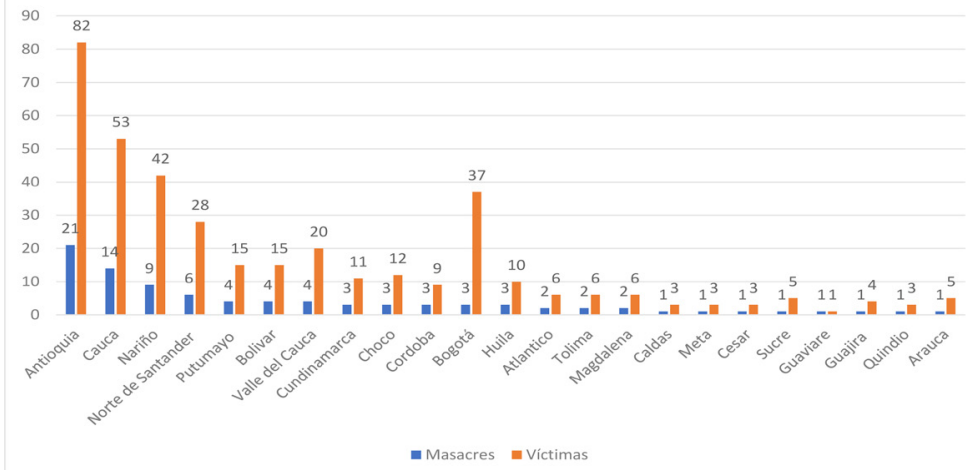

Fuente: Instituto de estudios para el desarrollo y la paz (INDEPAZ, 2021).

La Figura 2, en tanto, muestra que el suroccidente del país es la segunda zona del país con mayor número de masacres durante 2020. Se trata de región afectada por la exclusión social de las comunidades indígenas, cultivos ilícitos, desplazamiento forzoso, disputas por el control de las rutas del narcotráfico hacia el océano Pacífico, hambre, violencia, desigualdad, corrupción y abandono estatal.

Figura 2.

Masacres por Municipio en el Departamento de Antioquia año 2020

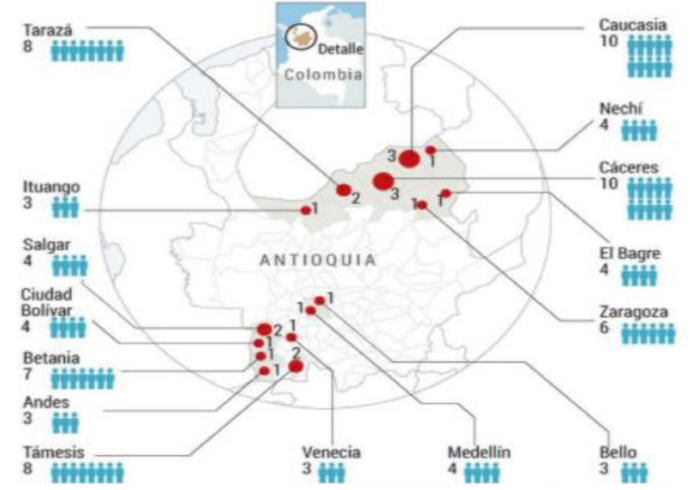

Fuente: El Espectador (2021b, s/p).

Por su parte, la Figura 3 muestra que la costa atlántica colombiana, escenario principal del accionar de grupos paramilitares, con cultivos 
ilícitos, contrabando y disputas por el control de las rutas del narcotráfico hacia el océano Atlántico, es la tercera zona del país con mayor número de masacres en Colombia.

Figura 3.

Masacres por Municipio suroccidente de Colombia

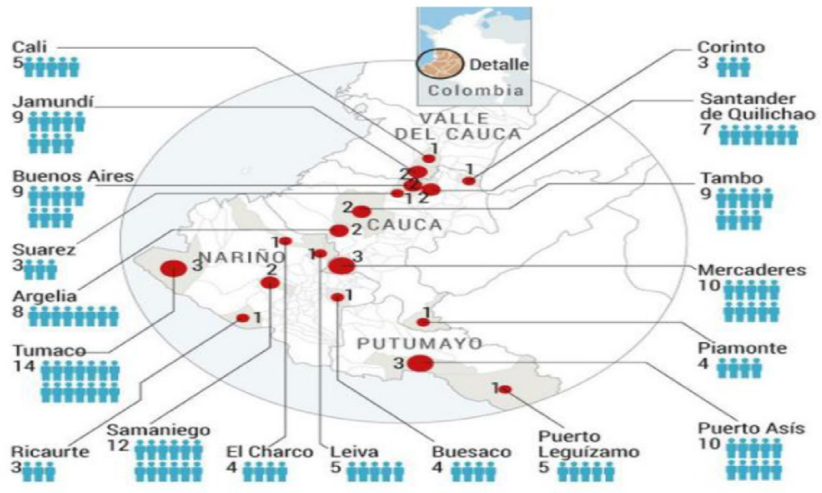

Fuente: El Espectador (2021b).

En tanto, como se aprecia en la Figura 4, la frontera con Venezuela se convierte en la cuarta zona en términos del número de masacres en Colombia durante 2020, seguida de la zona nororiente del país, como se muestra en la Figura 5.

Figura 4.

Masacres por Municipio costa atlántica colombiana

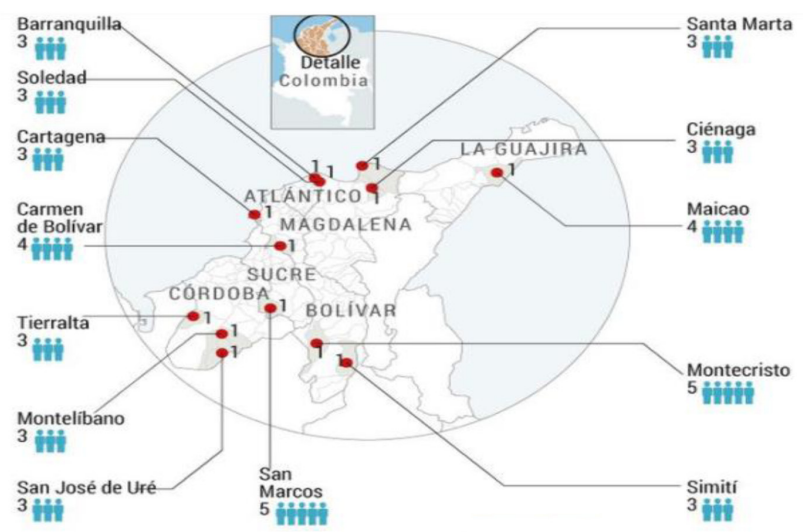

Fuente: El Espectador (2021b). 
Figura 5.

Masacres por Municipio nororiente de Colombia

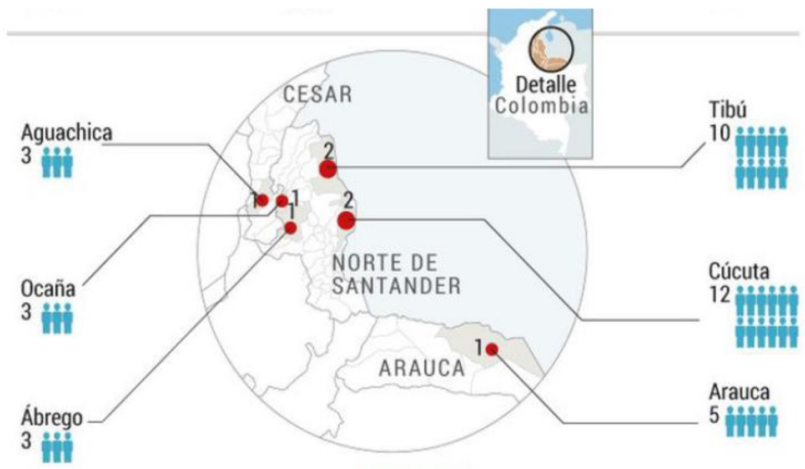

Fuente: El Espectador (2021b).

En el resto del país las masacres se distribuyen como indica la Figura 6. Especial atención llama el Departamento del Chocó en la costa pacífica colombiano, víctima la violencia relacionada con el control de las rutas del narcotráfico, la corrupción el abandono estatal, la corrupción y el racismo, así como las masacres en la capital Bogotá y el municipio vecino de Soacha.

Figura 6.

Masacres por Municipio resto de Colombia

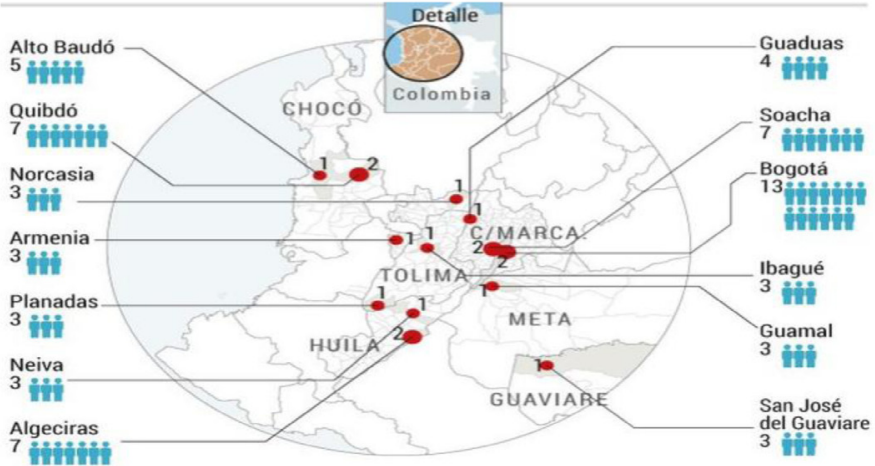

Fuente: El Espectador (2021b). 


\section{El caso Bogotá: autoritarismo neoliberal}

Como señalan Rodríguez Castillo et al. (2021), Bogotá se constituye en un escenario que alberga una cantidad importante de demandas y exigencias nacionales, por lo tanto, y fruto del impacto de las medidas neoliberales en el país, es escenario de pugna por la exigencia y el reconocimiento de derechos vulnerados durante las dos últimas décadas, lo que se expresa a través de agendas de movilización y de ocupación política del espacio público.

Durante 2019, se presentó un incremento en las movilizaciones ciudadanas en la capital del país. En noviembre se verificó la gran movilización del Paro nacional, donde la respuesta de la fuerza pública fue letal y culminó con el asesinato del joven estudiante de Bachillerato Dilan Cruz por parte de un miembro del Escuadrón Móvil Antidisturbios de la Policía (ESMAD). La criminalización y el tratamiento de guerra que se le sigue dando a la participación y a la movilización ciudadana cada día es más constante y visible. Tanto es así que, además de incrementarse de manera exorbitante casos de líderes sociales, estudiantiles y comunales inmersos en investigaciones judiciales, se evidencia la violación de protocolos sobre el actuar y el uso desmedido y desproporcional de la fuerza de la Policía Nacional en escenarios de movilización social.

Para 2020 se presentó un incremento en las agendas de protesta social con un total de 686 actividades registradas, esto es, un aumento de $104.1 \%$ en comparación con el año inmediatamente anterior. Este crecimiento puede atribuirse a las condiciones sociales de la ciudadanía producto de la emergencia del COVID-19 y, a su vez, en el crecimiento de las tensiones políticas de la agenda pública nacional.

El ejercicio del derecho a la protesta social durante el periodo 2020 en Bogotá se vio enmarcado por la crisis económica, social y ambiental agudizada por la propagación de COVID-19, el confinamiento y el impacto en las comunidades más vulnerables e históricamente excluidas de la ciudad.

Pese al confinamiento, para noviembre de 2020 se verificó un total de 786 escenarios de protesta social (movilización, plantón, toma, etc.) —siendo septiembre el mes con más actividades de protesta social, pues se registraron 234 acciones de movilización-, en su 
mayoría, en ocasión de la masacre perpetuada por la Policía Nacional posterior al asesinato de Javier Ordoñez ${ }^{2}$ y otras 11 personas en el distrito capital (Rodríguez Castillo et al., 2021, p. 17).

Figura 7.

Eventos de protesta social en Bogotá 2016-2020

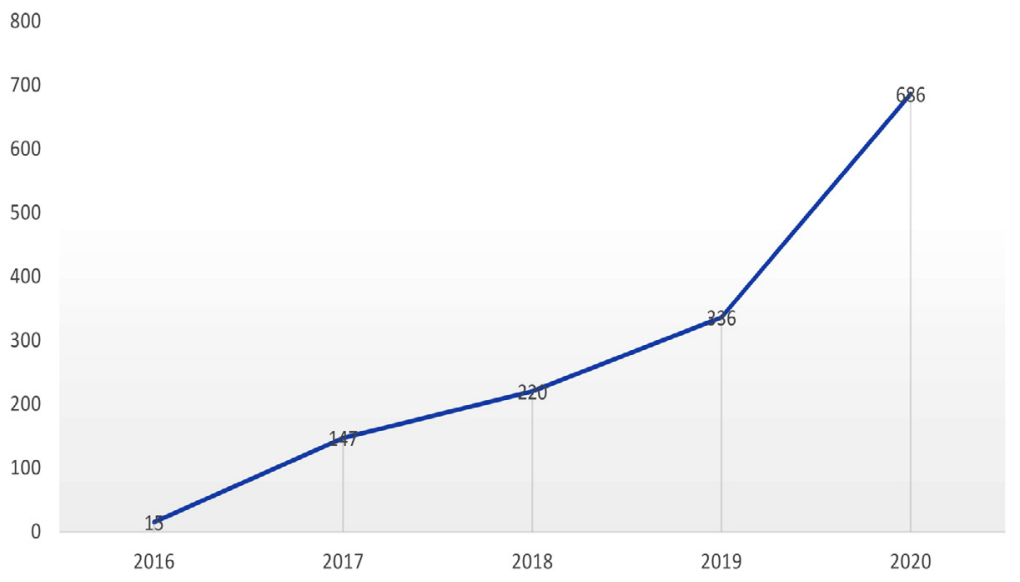

Fuente: Rodríguez Castillo et al. (2021).

Los mismos autores identifican patrones donde se evidencia la vulneración directa del derecho a la protesta, a saber:

- Estigmatización, allanamiento y montajes judiciales.

- Violación de protocolos y uso desmedido de la fuerza por parte de la Policía Nacional.

- Violencia policial en el marco de la protesta social.

- Agresión a defensoras de derechos humanos.

2 El 8 de septiembre de 2020, agentes de la Policía Nacional, en medio de un procedimiento policial, asesinaron brutalmente al abogado e ingeniero Javier Ordóñez en el Comando de Atención Inmediata (CAI) del barrio Villa Luz (Engativá), al occidente de Bogotá, causando indignación en sectores de la población civil, sectores políticos y organizaciones sociales, los cuales convocan manifestaciones pacíficas en respuesta a diversos casos de brutalidad policial que se han presentado en Colombia, especialmente los ocurridos en el marco de la crisis social y económica producida por la pandemia COVID-19 y el Paro nacional del 21 de noviembre de 2019. 
Figura 8.

Movilización social en Bogotá por mes en 2020

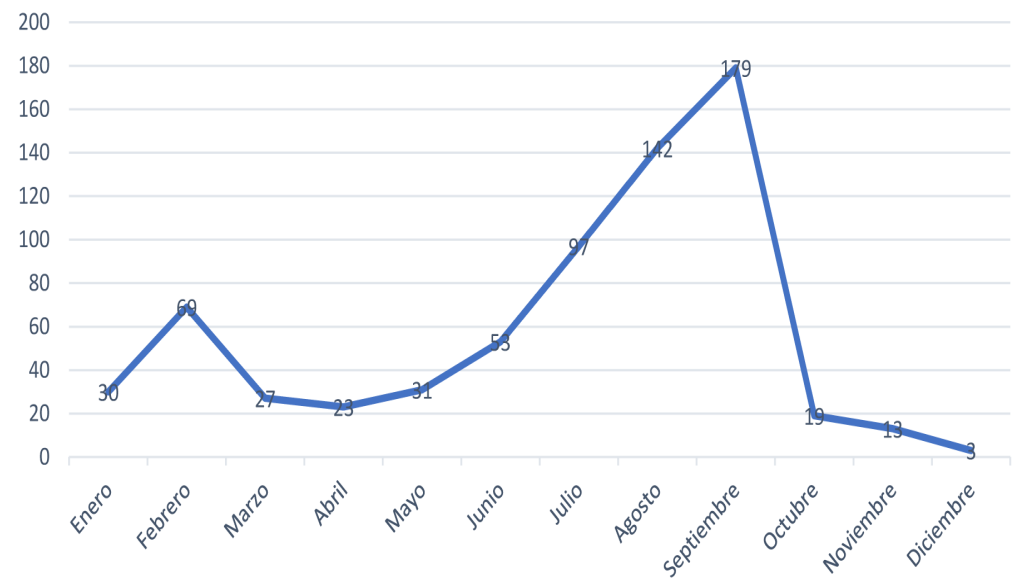

Fuente: Rodríguez Castillo et al. (2021).

Como profundizan los mismos autores:

En el marco de las movilizaciones que han tenido lugar desde el gran Paro nacional del 21 de noviembre de 2019 en las diferentes ciudades del país, el uso desproporcionado y desmedido de la fuerza por parte de la Policía Nacional, se ha convertido en una práctica reiterada. Las personas manifestantes pese a encontrarse desarrollando de manera plena su legítimo derecho a la protesta social han sido vulneradas y reprimidas durante las movilizaciones que se han suscitado durante el periodo 2020 en la ciudad de Bogotá. (Rodríguez Castillo et al., 2021, p. 19).

La Figura 7 muestra que en el primer semestre de 2020 se reportó un total general de 592 casos de violencia policial distribuidos en atención de las fechas de ocurrencia. 
Figura 9.

Casos de violencia policial Bogotá 2020

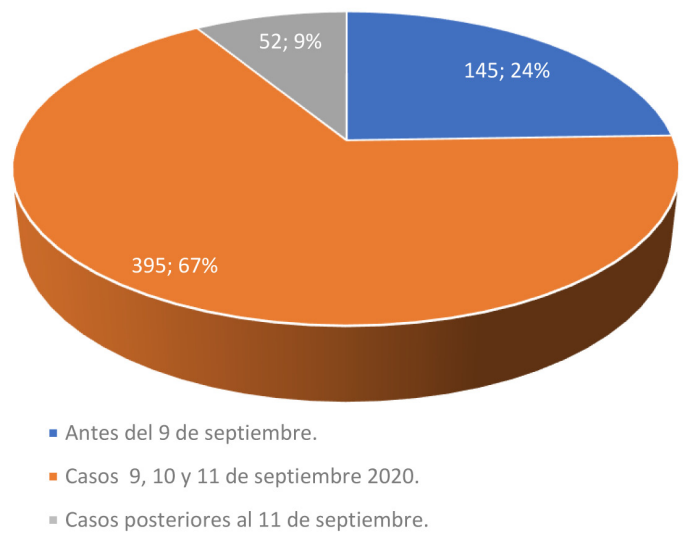

Fuente: Rodríguez Castillo et al. (2021).

Se puede apreciar que de acuerdo con el total de casos, el $67 \%$ se ubica en relación con los hechos de protesta del 9, 10 y 11 de septiembre, producto del asesinato de Javier Ordoñez. Adicionalmente, los casos previos al 9 de septiembre se encuentran ubicados en los periodos de aislamiento o cuarentenas debido a la emergencia del COVID-19, es decir, el $91 \%$ de los casos de violencia policial durante 2020 se produjo en el período de aislamiento estricto decretado por los gobiernos nacional y local. Pareciera que el aislamiento obligatorio fue interpretado por los miembros de la fuerza pública como una patente para abusar de su autoridad.

Así mismo, las principales víctimas de la violencia policial materializada en homicidios fueron jóvenes. En efecto, de los 11 asesinados en los tres nefastos días posteriores a la muerte de Javier Ordoñez, dos eran menores de edad; ocho asesinados tenían entrel8 y 29 años; y la última víctima tenía 36 años. Lo anterior muestra que "los jóvenes son un foco de agresión, persecución y estigmatización constante por parte de la institución policial" (Rodríguez Castillo et al., 2021, p. 30). 
Figura 10.

Víctimas de violencia policial en Bogotá por edades año 2020

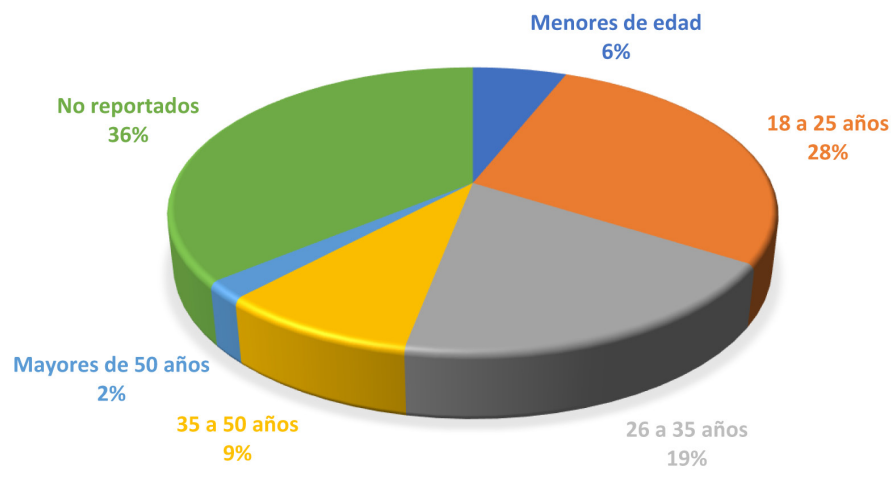

Fuente: Rodríguez Castillo et al. (2021).

Frente a los excesos de la fuerza pública, el gobierno de Duque salió a estructurar un discurso en el que respaldó a la Policía Nacional, con el manido recurso de:

- unas cuantas manzanas podridas (el mismo argumento que utilizan para referirse a los asesinatos cometidos por la fuerza pública, los mal llamados falsos positivos);

- que de ninguna manera es un patrón de comportamiento institucional (la presente investigación demuestra que sí existe un patrón); y

- que los responsables serán separados de la institución y afrontarán todo el peso de la ley.

Paso seguido, el presidente Duque se disfrazó de policía y convocó a los medios masivos tradicionales para que captaran sus imágenes de apoyo desde la institución presidencial hacia la Policía Nacional.

\section{Violencia estructural}

Es necesario señalar que el concepto de violencia estructural hace referencia a situaciones en las que se deteriora la satisfacción de las necesidades humanas básicas, aunque no sean formas de violencia directa. En este sentido, durante la pandemia COVID-19 en Colombia ha disminuido la satisfacción de necesidades humanas en general, pero mucho más las de las comunidades más vulnerables, excluidas y víctimas de las dinámicas descritas a lo largo de este texto. 
Rodríguez (2021) señala que durante 2020 el desempleo se incrementó, en tanto que la compra y venta de mercancías se ha visto fuertemente obstaculizada, golpeando los ingresos del trabajo y del capital. Según el Departamento Administrativo de Estadística (DANE), la situación laboral más grave se registró en el mes de mayo de ese año, cuando la población ocupada se redujo a 17,3 millones, esto es, un $22 \%$ menos que en 2019. La pérdida de empleos fue severa entre marzo y mayo de 2020, cuando el desempleo pasó del 12,6\% al 21,4\%, tal como se aprecia en la Figura 11.

Figura 11.

Tasa de desempleo mensual Colombia enero-diciembre 2020

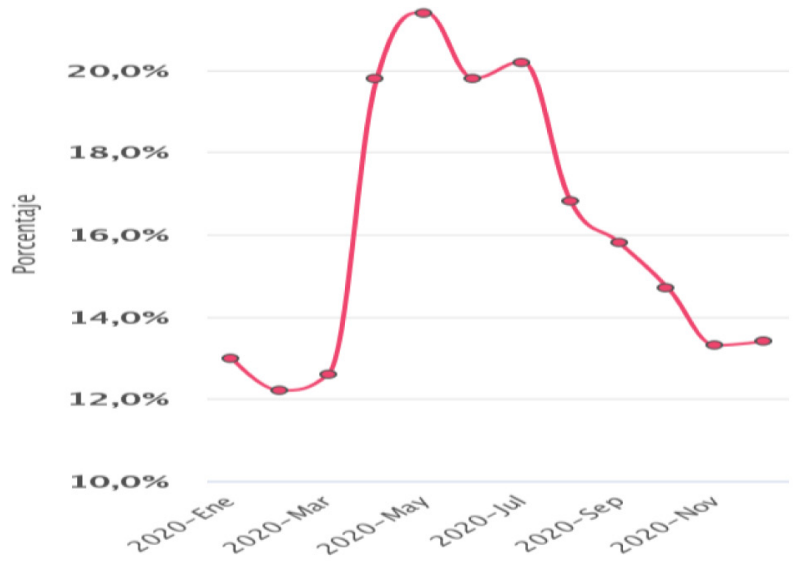

Fuente: Gran encuesta integrada de hogares (DANE, 2021).

Complementariamente, el desempleo ha variado en términos territoriales durante la pandemia:

La información del DANE se refiere a las ciudades y áreas metropolitanas. En todas ellas la desocupación primero aumentó entre marzo y mayo; y luego disminuye, pero se mantiene en niveles muy superiores a los que se presentaban en 2019 (Rodríguez, 2021, p. 255).

Lo anterior puede apreciarse en la Figura 12, donde se despliega la información relativa a la tasa de desempleo por regiones. 
Figura 12.

Tasa de desempleo por regiones segundo semestre 2019 versus 2020

\begin{tabular}{cccc}
\hline \multirow{2}{*}{ Indicador } & \multicolumn{3}{c}{ Tasa de desempleo (\%) } \\
\cline { 2 - 4 } & $\begin{array}{r}\text { II semestre } \\
202 \wedge^{\wedge}\end{array}$ & $\begin{array}{c}\text { II semestre } \\
2019\end{array}$ & $\begin{array}{c}\text { Diferencia en } \\
\text { p.p. }\end{array}$ \\
\hline Bogotá D.C. & 19,1 & 9,9 & $9,2^{*}$ \\
\hline Oriental & 15,7 & 10,5 & $5,3^{*}$ \\
\hline Central & 15,7 & 11,0 & $4,7^{*}$ \\
\hline Pacífica & 15,3 & 10,3 & $5,1^{*}$ \\
\hline Caribe & 12,3 & 8,5 & $3,8^{*}$ \\
\hline $\begin{array}{l}\text { (p.p.): Puntos porcentuales } \\
\text { ^Ordenado de mayor a menor } \\
\text { * Variación estadísticamente significativa }\end{array}$ \\
\hline
\end{tabular}

Fuente: Gran encuesta integrada de hogares (DANE, 2021).

Algo similar sucede con el desempleo por género y edad. Según Rodríguez (2021) en el período julio-septiembre de 2020, la tasa de desempleo de las mujeres llegó al 22,8\%, mientras que la de los hombres fue del 13,9\%. Comparando estos porcentajes con el mismo trimestre de 2019, el desempleo aumentó algo más de 9 puntos porcentuales entre las mujeres y cerca de 6 puntos entre los hombres. Durante el trimestre junio-agosto, en tanto, el desempleo juvenil pasó de un $18 \%$ al $28 \%$ entre 2019 y 2020. Las cifras desplegadas indican que el sector más vulnerable frente al desempleo en Colombia son las mujeres y los jóvenes.

$\mathrm{Al}$ respecto, los programas que el gobierno de Duque ha puesto en marcha durante el estado de emergencia y su ejecución presentan varios cuestionamientos. Por ejemplo, el Programa de Apoyo al Empleo Formal (PAEF), que busca otorgar un subsidio mensual para pagar la nómina a empresarios formales correspondiente al $40 \%$ del salario mínimo por trabajador contratado. Para Rodríguez (2021) a partir de datos obtenidos por la Unidad de Pensiones y Parafiscales, hasta el 25 de octubre de 2020 el total girado por este subsidio era de 3,1 billones de pesos (un pequeño $0,3 \%$ del PIB), que no se compadece con el peso relativo de obreros y empleados particulares en la fuerza laboral.

Así mismo, el programa Ingreso Solidario, que fue creado en abril para entregar de manera transitoria una transferencia monetaria 
para los hogares en situación de pobreza y vulnerabilidad que no son beneficiarios de programas sociales por parte del Estado, presenta graves fallas al momento de identificar beneficiarios y girar los recursos. Rodríguez (2021) indica a partir de datos del Departamento Nacional de Planeación (DNP), que el número de hogares beneficiados por Ingreso Solidario supera los 2,6 millones, en tanto que la suma total transferida hasta finales de octubre sería de unos 4 billones, es decir, un $0,4 \%$ del PIB.

En la misma línea, el gobierno ofreció entregar garantías para que las pequeñas y medianas empresas acudieran a préstamos para pagar la nómina y financiar capital de trabajo. El respaldo se extendió a las microempresas y a los trabajadores independientes. Según Rodríguez (2021) el monto asignado a estos programas de garantías (17,2 billones de pesos) corresponde a cupos anunciados y se giraron directamente a la banca privada, un oligopolio que financia campañas políticas y define buena parte de la política económica del país. A finales de octubre las entidades financieras solo habían desembolsado el $51 \%$ del crédito respaldado por esas garantías.

Rodríguez (2021) también se cuestiona que el Gobierno nacional destine recursos públicos para salvar empresas privadas, en lugar de generar políticas públicas de carácter general, e imparciales entre empresas: "No es justificable seleccionar en forma arbitraria a ganadores o perdedores específicos" (p. 260).

Al momento de someter este artículo a la revista, el gobierno colombiano se encontraba preparando el proyecto de ley que radicará en el congreso la tercera reforma tributaria del actual mandato denominada "Solidaridad Sostenible", con el argumento de hacer frente al alto endeudamiento producto de la pandemia COVID-19. Sin embargo, al analizar la propuesta se identifica que es más de lo mismo: una más de múltiples reformas que se han aplicado desde los años 90 que refuerza la concentración del ingreso en el segundo país más desigual de América Latina, que es la región más desigual del planeta.

$\mathrm{Al}$ respecto, la estructura tributaria de un país puede ser progresiva o regresiva. Una estructura progresiva implica que se utilizan los impuestos para transferir recursos de los sectores que tienen mayor ingreso, procedente de salarios, rentas y rendimientos de capital, a los 
sectores más vulnerables a través de impuestos directos a la renta, al capital y a la propiedad, lo que permite financiar inversiones en infraestructura, saneamiento básico, salud, educación para fortalecer las capacidades de los sectores de menores ingresos.

Una estructura tributaria regresiva - que es la que se evidencia a partir de las políticas neoliberales en América latina y Colombia aplicadas durante los últimos 30 años-, recibe recursos a partir de impuestos indirectos como el IVA que, por supuesto, graba la totalidad del ingreso de los sectores más vulnerables, y otorga grandes exenciones tributarias al gran capital, bajo el argumento de generar más empleos y mejorar la competitividad.

Lo anterior, como dice Villabona Robayo (2021), convierte a Colombia en un paraíso fiscal para los ricos, al tener un alto coeficiente de Gini ${ }^{3}$, que es el reflejo de una política fiscal inadecuada y regresiva que permite una alta concentración del ingreso y la riqueza.

Este coeficiente se calcula como un área bajo una curva. Se toman como referencia dos ejes, en el eje y se ubica la variable sobre la cual se quiere indagar la concentración, (ingreso, propiedad de la tierra) y en el eje $\mathrm{x}$ la población dividida en deciles o quintiles. Se traza en primer lugar la línea de equidistribución, una diagonal perfecta de 45 grados, que se explica en el sentido que se esperaría que al $10 \%$ de la población le corresponde el $10 \%$ del ingreso o de propiedad de la tierra y así sucesivamente hasta llegar al $100 \%$. Lo anterior efectivamente no sucede en ningún país del mundo. Lo que realmente ocurre es lo que refleja la curva de Lorenz, que registra lo que sucede con el ingreso y la propiedad de la tierra. De esta manera, el decil o el quintil inferior participa de manera ínfima en el PIB o la propiedad de la tierra, mientras que el decil superior se apropia de la mayoría del ingreso y de la tierra.

3 Indicador que sirve para medir la desigualdad, donde 1 representa la máxima desigualdad y 0 la equidad absoluta. 
Figura 13.

Cómo se calcula el coeficiente de Gini

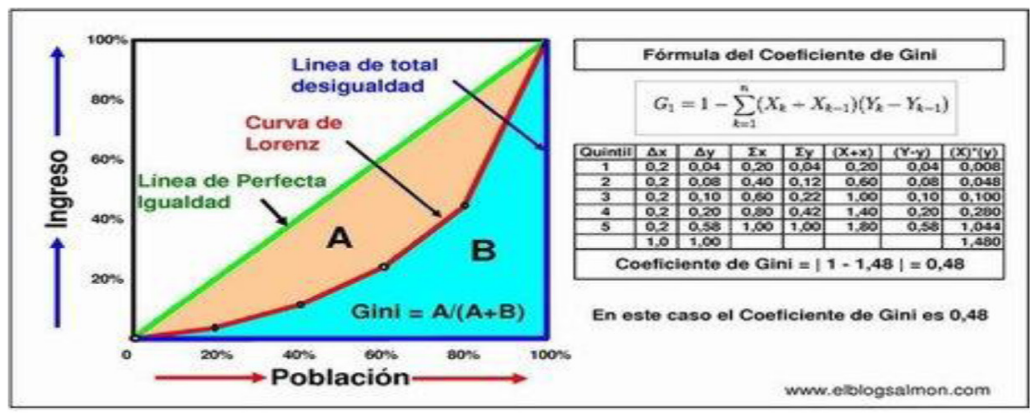

Fuente: El Blog Salmón (2010).

Si la curva de Lorenz se aleja de la línea de equidistribución, aumenta la desigualdad a la misma velocidad que aumenta el área "A". Si la desigualdad es total, el área $\mathrm{B}$ desaparece y queda solo el área $\mathrm{A}$, lo que indica que una sola familia se queda con el total de los ingresos (línea azul), es decir, un valor de 1. Si existiera perfecta distribución, la curva de Lorenz y la línea de equidistribución sería la misma línea, por lo tanto, el área bajo la curva sería 0 .

En el ejemplo de la Figura 13 el primer quintil (20\% de la población) se queda con el $4 \%$ del ingreso; el $40 \%$ de la población, con el 12\% (aumenta un $8 \%$ en relación con el primero), el $60 \%$ con el $22 \%$ del ingreso y el $80 \%$ de la población con el $42 \%$ del ingreso acumulado. En este caso, el Coeficiente de Gini es 0,48 (El Blog Salmón, 2010).

Aclarado en este punto, es necesario recordar que América Latina es la región más desigual del planeta, y que Brasil y Colombia son los países que presentan un mayor coeficiente de Gini, es decir, son los países más desiguales de la región. Según la Comisión Económica para América Latina y el Caribe (CEPAL, 2020), los efectos de la pandemia y de las medidas adoptadas por los gobiernos latinoamericanos traerán como efecto la agudización de la desigualdad y se estima que el coeficiente Gini aumentará en promedio 4,9\% en la región. Para el caso colombiano, el organismo proyecta un incremento de entre 4,0\% y 4,9\% en el mencionado coeficiente, que en el mejor de los casos sería de $54,8 \%$ para 2021. 
Figura 14.

Coeficiente Gini América Latina 2019

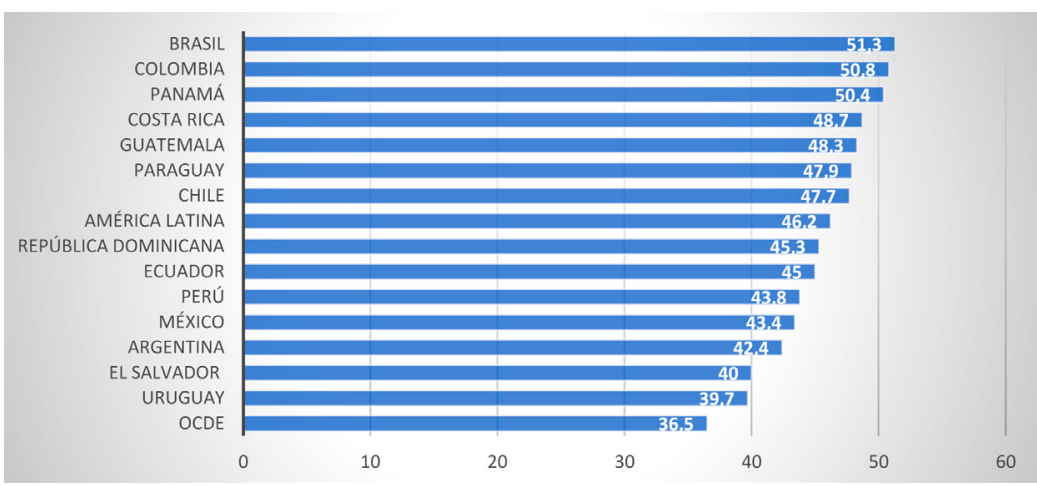

Fuente: CEPAL (2019).

Así mismo América Latina también es la región del mundo más desigual en términos de concentración de la propiedad de la tierra. Según We Effect (2021) el coeficiente de Gini de la propiedad de la tierra en Europa es el 0,57; en África de 0,56; en Asia de 0,55 y en América Latina de 0,79. En esta región, las personas que viven de la agricultura familiar, campesina e indígena son propietarias del $13 \%$ del total del área agrícola. En Colombia el dato es dramático: las personas que viven de la agricultura familiar, campesina e indígena son propietarias del $4 \%$ del total del área agrícola.

El proyecto de reforma tributaria presentado por el gobierno de Duque está lleno de beneficios tributarios dirigidos a los mismos beneficiarios de siempre: grupos económicos que financian las campañas políticas para la Presidencia y el Congreso, los que elaboran leyes que los favorecen, planes de desarrollo, políticas y proyectos donde resultan seleccionados como contratistas con sobrecostos e ineficiencias evidentes. Todo ello contribuye a reforzar la desigualdad estructural que se presenta en el país.

En acuerdo con Villabona Robayo (2021) la reforma presentada es regresiva, ya que la estructura tributaria del país busca gravar con IVA varios bienes de la canasta familiar y aumentar del $5 \%$ al $12 \%$ varios bienes de primera necesidad, afectando el consumo de los sectores más vulnerables de la población. En Colombia ser rico es un gran privilegio para no pagar impuestos o pagar impuestos inmateriales, lo que permite afirmar que el sistema tributario colombiano es un complejo e injusto. 
$\mathrm{Al}$ respecto, CEPAL (2020) señala que la pandemia COVID-19 profundizó la desigualdad, la baja productividad y la fragmentación de acceso a la salud y a la protección social, propias del modelo neoliberal que durante tres décadas ha concentrado la riqueza, deteriorado los ecosistemas, consolidado instituciones que reproducen comportamientos de agentes con mayor poder económico y político y naturalizado una cultura del privilegio, que justifica jerarquías sociales, desigualdades, discriminación y el patriarcado.

En consonancia con Garay Salamanca (2021) la pandemia agudiza la crisis estructural del sistema sanitario colombiano, y evidencia los peligros asociados a la mercantilización del servicio de salud, su terciarización, la insuficiencia de infraestructura, instalaciones, equipamiento, condiciones laborales indignas del personal sanitario, fragilidad del sistema público de salud, desigualdad de acceso entre entes territoriales, una regulación institucional precaria y selectiva y la operación del sistema por múltiples empresas intermediarias - con ineficiente capacidad y elevados costos de transacción - finalmente desperdician recursos públicos y afectan la adecuada y oportuna atención de la población. En este sentido, posiblemente lo más cuestionable del sistema de salud colombiano es:

La reproducción de graves daños sociales, colectivos e individuales, resultantes de la inadecuada o nula prestación de servicios respecto de lo requerido por muchos de los enfermos, en particular de poblaciones pobres y vulnerables, mediante la utilización de muy diversos esquemas de organización entre personas naturales y empresas prestadoras de servicios - legales o incluso de "fachada" - y de estrategias y mecanismos de apropiación indebida de recursos públicos - con la configuración de redes de macrocorrupción y cooptación institucional. (Garay Salamanca, 2021, p. 6).

En síntesis, la pandemia del COVID-19 profundizó las fracturas e injusticias sociales existentes en el país. Una evidente muestra de lo anterior es el proceso de vacunación que se ha dado en Colombia. A finales de 2020 el presidente Iván Duque anunció el plan de vacunación cuya meta es lograr que el $70 \%$ de población esté inmunizada al cierre de 2021. Sin embargo, al día de hoy solo se ha administrado dosis a un 2,5\% de su población (Galindo, 2021). Según el mismo autor, el gobierno colombiano no cerró acuerdos o preacuerdos con la prontitud de 
otros países de la región, a lo que se suman todos los factores previamente descritos que generan asimetrías en la eficacia y colaboración con el sector público, con altos índices de corrupción y desigualdades territoriales que dificultan la probabilidad de recibir una dosis.

Lo anterior se evidencia en la proporción entre las dosis empleadas y las recibidas para cada uno de los departamentos y municipios. lo anterior implica que aún siendo optimistas y esperando que se cumpla el ambicioso objetivo de un $70 \%$ de la población inmunizada ante el virus, este porcentaje se concentrará - posiblemente- en los principales centros urbanos, excluyendo a los habitantes de las zonas más vulnerables del país. Este es el colofón de un reforzamiento de la violencia estructural hacia los mismos sectores victimizados de múltiples formas.

\section{Conclusión}

El análisis documental realizado evidencia cómo las categorías estado de excepción, autoritarismo neoliberal y biopolítica, permiten develar fenómenos sociales concretos causados por el tratamiento de la pandemia COVID-19 por parte del gobierno colombiano, durante el período de confinamiento comprendido entre marzo y septiembre de 2020. En dicha etapa se han intensificado en Colombia las violaciones al derecho internacional humanitario, la estigmatización y criminalización de la movilización social y la acción colectiva, las violaciones de los derechos humanos por parte de la fuerza pública, las masacres, el asesinato de líderes sociales, minorías étnicas y desmovilizados de las Fuerzas Armadas Revolucionarias de Colombia (FARC-EP). Lo mismo ha ocurrido con la violencia estructural asociada a la pobreza, las medidas sanitarias y el acceso de los colombianos más vulnerables a los servicios de salud y a la vacunación contra el SARS-CoV-2.

Como colofón siniestro de tal situación, se describen dos hechos que refuerzan lo planteado al momento de someter el presente artículo a consideración de la revista. En primer lugar, se conoce en Colombia de un nuevo bombardeo por parte de las fuerzas militares a un campamento de disidencias de las FARC en la región selvática del Guaviare en la Amazonía, a sabiendas que este grupo ilegal estaba reclutando menores de edad y que estos se encontraban en el campamento al momento del bombardeo, repitiendo así lo sucedido en noviembre de 2019 cuando en otro bombardeo ejecutado por la fuerza pública 
murieron 8 menores de edad. Dicha situación, causó la salida de quien era el ministro de Defensa en ese momento, Guillermo Botero, y ante el requerimiento por parte de un periodista de la postura del presidente de la República frente a tal situación, la respuesta de Iván Duque fue el tristemente conocido "De qué me hablas viejo".

Frente a las declaraciones emitidas por el actual ministro de defensa Diego Molano por el reciente bombardeo en el Guaviare, el diario El Espectador en su página editorial, manifiesta su preocupación en el siguiente sentido:

Las palabras empleadas por Molano muestran una concepción cruel, maniquea, facilista y francamente angustiante de la realidad colombiana. ¿Cómo no sentir vergüenza cuando se utilizan las mismas tácticas de los regímenes autoritarios para deshumanizar al enemigo? (El Espectador, 2021a).

Cabe recordar en ese sentido que el ministro de Defensa Molano afirmó que frente a la matanza de niños durante esos ataques que: "Están haciendo una afirmación de que había 12 niños. Lo que teníamos eran máquinas de guerra que estaban planeando acciones terroristas. Aquí lo que tenemos son niños que hacen parte de una estructura de guerra, capaz de cometer atentados" (El Espectador, 2021a). Continúa el medio de comunicación con la siguiente reflexión:

Al tildar a alguien de "máquina de guerra", Molano está cometiendo un acto de violencia simbólica a través del lenguaje. El "otro" desaparece, pierde su humanidad, se le arrebata cualquier atisbo de dignidad y se reduce a algo sin sentimientos, sin agencia, sin derechos, cuyo único propósito en la vida es cometer delitos. Esa destrucción del enemigo en el debate público es un truco utilizado a lo largo de la historia de la humanidad para no tener que responder por los abusos. Como ese "otro" es una máquina, ¿para qué molestarnos en preocuparnos por su vida? (El Espectador, 2021b).

Lo anterior legitima ese homo sacer construido por la comunidad inmunizada colombiana descrito en el presente artículo. Así mismo, las declaraciones del presidente Duque y sus ministros de Defensa evidencian una banalización de la violencia por parte del gobierno colombiano que es propia de la misma dinámica del estado de excepción y el autoritarismo neoliberal. 
El segundo hecho que refuerza lo descrito en estas líneas es la brutal respuesta del gobierno colombiano al Paro nacional que se llevó a cabo en Colombia desde el 28 de abril de 2021. Según la ONG Temblores (2021) en el marco de las protestas entre la fecha de inicio y el 25 de mayo de 2021 se han presentado 3.155 casos de violencia policial, 955 personas víctimas de violencia física por parte de la policía, 43 víctimas de violencia homicida presuntamente por parte de la policía, 1.388 detenciones arbitrarias, 595 intervenciones violentas por parte de la fuerza pública, 46 víctimas de agresión en sus ojos, 165 casos de disparos con armas de fuego por parte de la policía contra manifestantes inermes y22 víctimas de violencia sexual por parte de la fuerza pública.

Así mismo, según Deutsche Welle (2021) entre el 28 de abril y el 18 de mayo de 2021, el Mecanismo de Búsqueda Urgente (MBU) en Colombia registró 548 de personas presuntamente desaparecidas, de las cuales 261 fueron localizadas. Según la Defensoría del Pueblo, 89 personas habrían desaparecidos al 18 de mayo. Independientemente de la inconsistencia en las cifras, estas son preocupantes y mucho más cuando están apareciendo partes de cuerpos desmembrados en ciudades como Bogotá, Cali, zonas rurales y en Ríos, especialmente el Río Cauca.

El 27 de mayo de 2021, evidenciando el contubernio existente entre el gobierno de Duque y las mayorías que tiene en el congreso, el Senado de Colombia negó la moción de censura contra el ministro de Defensa Diego Molano y la Comisión segunda del mencionado Senado avaló el ascenso a general efectivo del director de la Policía, a pesar de las evidencias incontrovertibles de abuso por parte de la fuerza pública.

Frente a la arremetida de la política del miedo y el autoritarismo neoliberal, que instrumentalizaron la pandemia COVID-19 en Colombia, la biocracia y el cualsea brindan un norte a la acción colectiva y a la movilización social. En Colombia es urgente lograr ver en el otro: la víctima, la mujer, el migrante, el campesino, el indígena, el afrodescendiente, el líder social, el joven, el vendedor informal, el excombatiente, el excluido, el vulnerable a un cualsea y, de esta manera, aportar a la construcción de una nueva sociedad, en la que las relaciones sociales estén mediadas únicamente por la valorización de la vida. 


\section{Referencias}

Agamben, G. (1996). La comunidad que viene. Pre-textos.

Agamben, G. (1998). Homo sacer: el poder soberano y la nuda vida. Pre-textos.

Agamben, G. (2020). La invención de una epidemia. En P. Amadeo (Ed.), Sopa de Wuhan: pensamientos contemporáneos en tiempos de Pandemias (pp. 17-20). Aislamiento Social preventivo y Obligatorio.

Benjamin, W. (1940). Sobre el concepto de historia. https://crucecontemporaneo.files.wordpress.com/2015/05/sobre-el-concepto-de-historia.pdf

Burgos, E. (2020). Biopolítica, pandemia y autoritarismo en Venezuela. Temas de Comunicación, (40), 85-93. https://dialnet.unirioja.es $/$ servlet $/$ articulo? codigo $=7552844 \&$ orden $=0$ \&info $=$ link

Caldera Ynfante, J. E. (2020). Biocracia y derecho fundamental al nuevo orden mundial en la pospandemia COVID-19. Utopía y Praxis Latinoamericana, 25(4 extra), 33-49. https://produccioncientificaluz.org/index.php/utopia/article/view/32845

Comisión Económica para América Latina y el Caribe, CEPAL. (2019). Perspectivas económicas de América Latina 2019. Desarrollo en transición. CEPAL. https://www.cepal.org/sites/default/ files/publication/files/44525/S1900182_es.pdf

Comisión Económica para América Latina y el Caribe, CEPAL. (24 de noviembre de 2020). Desafíos sociales y económicos de América Latina y el Caribe en la pospandemia. CEPAL. https:// www.cepal.org/sites/default/files/presentations/presentacion_cepal_24112020.pdf

Correa, F. (2020). Capitalismo, pandemia y crisis global: reflexiones sobre la COVID-19 y nuevas formas editoriales. Dixit, (32), 76-80. https://doi.org/10.22235/d.vi32.2187

Da Rocha Seixas, R. (2020). Da biopolítica a necropolítica e a racionalidade neoliberal no contexto do COVID-19. Voluntas: Revista Internacional de Filosofia, (11), 1-11. https://doi. org/10.5902/2179378643939

Departamento Administrativo Nacional de Estadística, DANE. (25 de marzo de 2021). Gran encuesta integrada de hogares. Estadísticas por tema. DANE. https://www.dane.gov.co/index. php/estadisticas-por-tema 
Díaz Arias, D. y Viales Hurtado, R. (2020). Centroamérica: neoliberalismo y COVID-19. Geopolítica(s). Revista de estudios sobre espacio y poder, 11(especial), 53-59. https://doi.org/10.5209/ geop. 69017

Deutsche Welle (26 de mayo de 2021). Unión Europea-Colombia: ¿quién busca a los desaparecidos? DW. https://www.dw.com/ es/uni\%C3\%B3n-europea-colombia-qui\%C3\%A9n-buscaa-los-desaparecidos/a-57674213

El Blog Salmón. (1 de agosto de 2010). ¿Qué es el coeficiente de Gini? El Blog Salmón. https://www.elblogsalmon.com/conceptosde-economia/que-es-el-coeficiente-de-gini

El Espectador. (13 de marzo de 2021a). La violencia también se ejerce con el lenguaje. El Espectador. Editorial. https://www. elespectador.com/opinion/editorial/la-violencia-tambiense-ejerce-con-el-lenguaje/

El Espectador. (3 de enero de 2021b). Un año marcado por las masacres. El Espectador. https://www.elespectador. com/colombia2020/pais/un-ano-marcado-por-lasmasacres/\#: :text=El\%20a\%C3\%B10\%202020\%20cierra\%20 con,donde\%20asesinaron\%20a\%20tres\%20personas

Esposito, R. (2003). Communitas: origen y destino de la comunidad. Amorrortu.

Estupiñán Achury, L. (2020). COVID-19 y fragilidad del estado de derecho en América Latina. Revista de la Academia Colombiana de Jurisprudencia, 1(371), xvii-xxx. http://revistaacademiacolombianajurisprudencia.acj.org.co/index.php/revista_acj/article/view/84

Foucault, M. (1997). Defender la sociedad. Curso en el Collège de France (1975- 1976). Fondo de Cultura Económica.

Foucault, M. (1999). Vigilar y castigar. Nacimiento de la prisión. Siglo XXI editores.

Foucault, M. (2002). Historia de la sexualidad I: La voluntad de saber. Siglo XXI editores.

Foucault, M. (2009). Nacimiento de la biopolítica. Curso del Collège de France (1978-1979) (Vol. 283). Ediciones Akal.

Galindo, J. (24 de marzo de 2021). La vacunación no despega en Colombia. El País. https://elpais.com/internacional/2021-03-24/ la-vacunacion-no-despega-en-colombia.html 
Garay Salamanca, L. J. (2021). A propósito de la pandemia del COVID-19 y el modelo sanitario en Colombia. Revista Facultad Nacional de Salud Pública, 39(1), 5-7. https://doi.org/10.17533/ udea.rfnsp.e344253

Garzón Buenaventura, E. y Álvarez Orduz, V. (2020). Dilemas éticos, en la perspectiva del derecho administrativo global (Biopoder-Biopolítica) COVID-19. En Universidad Libre (Ed.), La codificación procesal constitucional de la Universidad Libre seccional Bogotá (pp. 168-195). Universidad Libre.

Hola News. (24 de marzo de 2021). CICR: Aún existen cinco conflictos en Colombia, que se agravaron con la pandemia. Hola News. https://holanews.com/cicr-aun-existen-cinco-conflictosen-colombia-que-se-agravaron-con-la-pandemia/

Human Rights Watch. (10 de febrero de 2021). Informe Mundial 2021. Colombia Eventos 2020. Human Rights Watch. https://www. hrw.org/es/world-report/2021/country-chapters/377396

Instituto de estudios para el desarrollo y la paz, INDEPAZ. (2021). Informe de masacres en Colombia durante el 2020-2021. INDEPAZ. http://www.indepaz.org.co/informe-de-masacresen-colombia-durante-el-2020/

Pachón Soto, D. (13 de 4 de 2020). El COVID-19, la vida y el ser humano cápsula. https://alponiente.com/el-COVID-19-la-vida-y-elser-humano-capsula/?fbclid=IwAR0kpvDP0gSZup6eoAZLz 85FKSyNuzSoC92n7hW-2mD01ctPymr9vRQvK58

Quintero Cordero, S. (2020). La inseguridad colectiva: respuestas a lo inesperado. Revista Científica General José María Córdova, 18(31), 547-564. https://doi.org/10.21830/19006586.615

Ramírez Gallegos, R. (5 de mayo de 2020). Dictaduras democráticas, autoritarismo neoliberal y revueltas populares en tiempos de COVID-19. Celag.org. https://www.celag.org/wp-content/uploads/2020/06/covid-dictaduras-democraticasweb.pdf

Rengifo López, J. (2020). La comunidad y el miedo: comportamiento de la sociedad colombiana durante los meses de cuarentena obligatoria por la crisis del COVID-19. Revista Miradas, 1(3), 143-165. https://doi.org/10.22517/25393812.24474

Rodríguez Castillo, A. C., Fajardo Pulido, I., Correa, C. F., Triviño López, N., Esguerra Neuta, M., y Aldana, A. F. (2021). El derecho a defender. Primer informe sobre la situación de Derechos $\mathrm{Hu}$ - 
manos en Bogotá 2020. Red Popular de Derechos Humanos, Fundación Lazos de Dignidad, Alternativa.

Rodríguez, J. A. (2021). Situación económica, política fiscal y pandemia en Colombia. Revista de Economía Institucional, (44), 249263.

Schubert, K. (1 de abril de 2020). Crying for Repression: Populist and Democratic Biopolitics in Times of COVID-19. https://criticallegalthinking.com/2020/04/01/crying-for-repression-populist-and-democratic-biopolitics-in-times-of-COVID-19/

Temblores.org. (25 de mayo de 2021). Comunicado a la opinión pública y a la comunidad internacional por los hechos de violencia física y homicida cometidos por la Policía Nacional de Colombia en el marco de las movilizaciones del Paro Nacional. Temblores.org. https://www.temblores.org/comunicados

Villabona Robayo, J. O. (25 de marzo de 2021). Colombia, un paraíso fiscal para los ricos. https://unperiodico.unal.edu.co/pages/ detail/colombia-un-paraiso-fiscal-para-los-ricos/?fbclid=I wAR1LVDSFOyvdT8Y2tY27qS2dPytLapErqjV2tHRTYJs0iH2 szq-iMPBVIDA

We Effect. (4 de enero de 2021). América Latina tiene la mayor desigualdad del mundo en distribución de la tierra. We effect. https:// latin.weeffect.org/news/america-latina-tiene-la-mayordesigualdad-del-mundo-en-distribucion-de-la-tierra/ 